\title{
PENERAPAN METODE MARKER BASED TRACKING AUGMENTED REALITY PESUT MAHAKAM
}

\author{
Muhammad Bambang Firdaus'), Edy Budiman²), Fernando Elda Pati³), \\ Andi Tejawati' ${ }^{4)}$, Lathifah ${ }^{5)}$, M. Khairul Anam ${ }^{6}$ \\ ${ }^{1,2,3,4}$ Informatika, Universitas Mulawarman \\ ${ }^{5}$ Informatika, Universitas Teknokrat \\ ${ }^{6}$ Teknologi Informasi, Stmik Amik Riau \\ 1,2,3,4 Kampus Gn Kelua Jl. Kuaro, Samarinda \\ ${ }^{5}$ Jl. ZA. Pagar Alam No.9 -11, Bandar Lampung \\ ${ }^{6}$ Jl. Purwodadi Indah, Pekanbaru \\ Email: 'bambangf@fkti.unmul.ac.id, ${ }^{2} e d y . b u d i m a n @ f k t i . u n m u l . a c . i d$, \\ 3nandoe08@gmail.com, ${ }^{4} t e j a w a t i a n d i @ g m a i l . c o m,{ }^{5}$ lathifah@teknokrat.ac.id, ${ }^{6} k$ hairulanam@sar.ac.id
}

\begin{abstract}
The only freshwater pesut owned by Indonesia is the Pesut-Mahakam, or its Latin name Orcaella brevirotis. The pesutMahakam belongs to the category of critically endangered and endangered animals. This study aims to produce an application with an increase in reality that can socialize and educate about Pesut-Mahakam, an Android-based company. Software development process model for Rapid Application Development. Software testing is done through Marker Test and System Functionality Test. The test results show that the Augmented Reality 3D Pesut-Mahakam application is feasible and able to socialize and provide education as expected.
\end{abstract}

Keyword: Pesut Mahakam, Augmented Reality, Marker Based Tracking

\begin{abstract}
Abstrak
Satu-satunya lumba-lumba air tawar yang dimiliki Indonesia adalah Pesut-Mahakam, atau nama latinnya Orcaella brevirotis. Pesut-Mahakam termasuk dalam kategori hewan yang sangat terancam dan hampir punah. Penelitian ini bertujuan untuk menghasilkan sebuah aplikasi dengan peningkatan realitas yang dapat mensosialisasikan dan mengedukasi tentang Pesut-Mahakam, sebuah perusahaan berbasis Android. Model proses pengembangan perangkat lunak untuk pengembangan aplikasi yang cepat. Pengujian perangkat lunak dilakukan melalui Tes Penanda dan Tes Fungsionalitas Sistem. Hasil pengujian menunjukkan bahwa aplikasi Augmented Reality 3D Pesut-Mahakam ini layak dan mampu bersosialisasi dan memberikan edukasi seperti yang diharapkan.
\end{abstract}

Kata Kunci: Pesut Mahakam, Augmented Reality, Marker Based Tracking

\section{Pendahuluan}

Satu-satunya lumba-lumba air tawar yang dimiliki Indonesia adalah Pesut-Mahakam, atau nama latinnya Orcaella Brevirotis. Orang menyebutnya Pesut, nama yang diambil dari penduduk setempat di sungai Mahakam, Kalimantan Timur. Pesut-Mahakam adalah mamalia air tawar Kalimantan timur yang hidup di Sungai Mahakam. Mamalia ini merupakan lambang Provinsi Kalimantan Timur dan merupakan satwa yang dilindungi [1].

Pesut Mahakam telah dinyatakan sebagai spesies yang sangat terancam punah dan sangat terancam punah (Cryptically Endangered Species) oleh International United of Conservation of Natural and Natural Resources, IUCN sejak tahun 2000 [2]. Pesut Mahakam sebagai lambang Provinsi Kalimantan Timur diperkirakan tersisa
75-80 individu saja pada tahun 2014 oleh Yayasan RASI. Pemerintah dan masyarakat harus melindungi dan melestarikan satwa langka, karena merupakan kewajiban yang membutuhkan kerjasama untuk mengatasi ancaman yang ada [3].

Teknologi virtual saat ini telah berkembang sangat cepat dan diantaranya adalah Augmented Reality yang secara umum merupakan penggabungan objek virtual dengan objek nyata yang kemudian menghasilkan objek tiga dimensi (3D) [4]. Peningkatan teknologi adalah teknologi pengembangan dan minat untuk memberikan edukasi mengenai satwa lumba-lumba air tawar atau pesut Mahakam kepada masyrakat [5][6].

Peniliti berkeinginan untuk membangun aplikasi yang memberikan edukasi mengenai satwa pesut Mahakam yang merupakan simbol dari Kalimantan Timur 
yang saat ini terancam punah agar masyarakat tahu bahwa perlunya kepedulian terhadap pesut Mahakam [7]. Sehingga dengan aplikasi ini dapat mensosialisasikan mengenai pesut Mahakam dan memberikan edukasi kepada masyarakat agar melestarikan pesut Mahakam yang menjadi simbol Kalimantan Timur [8][9]. Tujuan dari penilitian adalah membuat aplikasi yang dapat mensosialisasikan dan memberikan edukasi mengenai pesut Mahakam dapat lebih dikenal oleh masyarakat dan juga generasi mendatang.

\section{Metode}

Aplikasi mobile dalam penelitian ini dibangun menggunakan model pengembangan Rapid Application Development $(R A D)$.

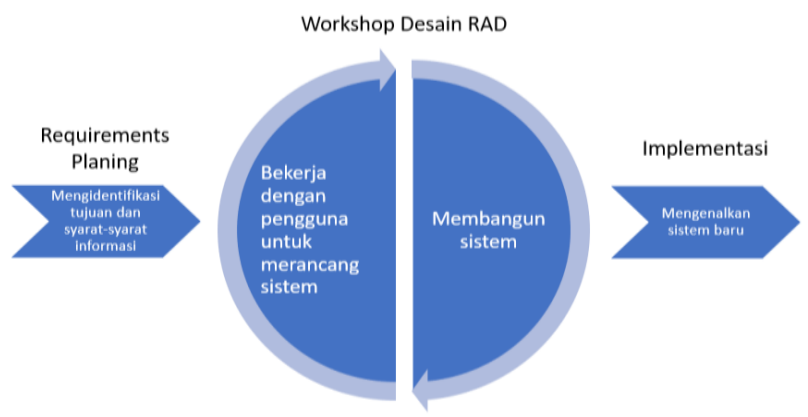

Gambar 1. Model Rapid Application Development

Pengembangan aplikasi yang cepat adalah pendekatan pengembangan sistem berorientasi objek yang mencakup perangkat lunak dan metode pengembangan [10]. Pesatnya perkembangan aplikasi bertujuan untuk memperpendek periode antara desain dan implementasi sistem informasi [11], biasanya diperlukan dalam siklus pengembangan tradisional sistem. Terakhir, Rapid Development Application bertujuan untuk memenuhi perubahan kebutuhan dengan cepat [12][13].

Adapun pada perancangan sistem yang akan dibangun menggunakan prosedur dalam pengembangan aplikasi ini yaitu seperti berikut :

A. Requirements Planning (Perencanaan Syarat-syarat) Pengguna dan penganalisis bertemu dalam fase ini untuk mengidentifikasi tujuan aplikasi atau sistem dan persyaratan informasi yang dihasilkan dari tujuan tersebut [14]. Pada fase ini, orientasinya adalah untuk menyelesaikan masalah [15]. Meskipun TI dan sistem dapat memandu beberapa sistem yang diusulkan, fokusnya tetap selalu pada pencapaian tujuan [16].

B. RAD Design Workshop (Workshop Desain RAD)

Fase ini merupakan fase perbaikan dan desain yang dapat digambarkan sebagai workshop [17]. Analis dan programmer dapat membuat tampilan visual dari desain dan pola kerja dan menunjukkannya kepada pengguna [18]. Tergantung pada ukuran aplikasi yang akan dikembangkan, lokakarya desain ini mungkin memakan waktu beberapa hari [19]. Pengguna menanggapi prototipe yang ada selama lokakarya desain RAD dan penganalisis menyempurnakan modul yang dirancang berdasarkan respon pengguna [20]. Upaya kreatif ini dapat mendorong pembangunan ke tingkat yang dipercepat jika pengembang yang sedang berkembang adalah orang yang berkembang yang berpengalaman [21].

\section{Implementation (Implementasi)}

Selama lokakarya, analis bekerja sama dengan pengguna dan merancang aspek korporat dan non-teknis perusahaan. Setelah aspek-aspek ini disetujui dan sistem telah dibangun dan disaring [22], organisasi akan menguji sistem atau bagian sistem baru dan kemudian memperkenalkannya [23].

\section{Hasil dan Analisis}

A. Implementasi Program

Implementasi program akan memberikan penjelasan meliputi implementasi interface dari aplikasi $A R$ yang telah dibangun [24], mulai dari interface halaman home sampai dengan implementasi interface dari objek 3D yang muncul saat kamera diarahkan ke marker.

\section{1) Interface Halaman Home}

Latar belakang interface halaman home menggunakan gambar desain pesut mahakam yang di animasikan untuk menggambarkan ketertarikan aplikasi ini dengan pesut mahakam. Terdapat 5 menu utama pada halaman home yaitu menu Scan AR untuk masuk ke halaman Scan AR, menu Instruction untuk masuk ke halaman petunjuk penggunaan aplikasi, kemudian menu marker untuk masuk ke halaman marker dari aplikasi, menu About untuk masuk ke halaman tentang aplikasi dan menu Keluar.

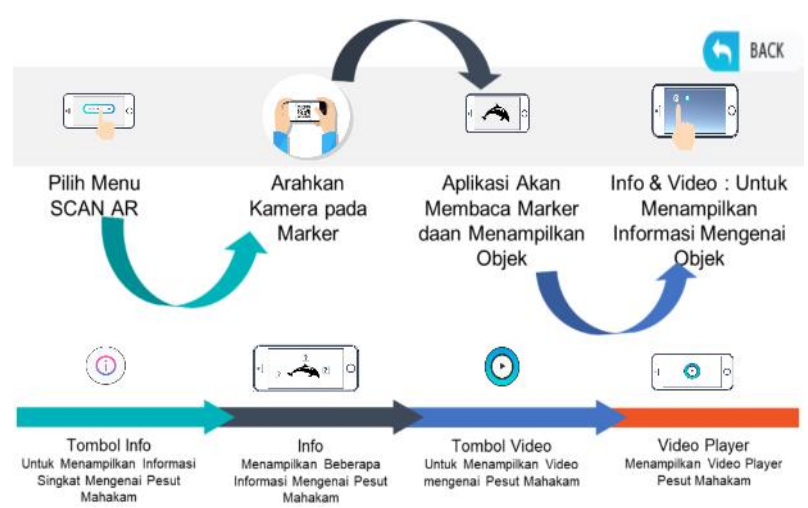

Gambar 2. Interface Halaman Home

\section{2) Interface Halaman Instruction}

Halaman Instruction merupakan halaman petunjuk dimana terdapat penjelasan umum mengenai cara penggunaan aplikasi Augmented Reality ini secara singkat [25]. Penjelasan dibuat sesingkat mungkin untuk dapat memberikan gambaran umum yang lebih jelas terutama bagi orang yang pertama kali menggunakan aplikasi ini mengenai cara penggunaan aplikasi ini. 


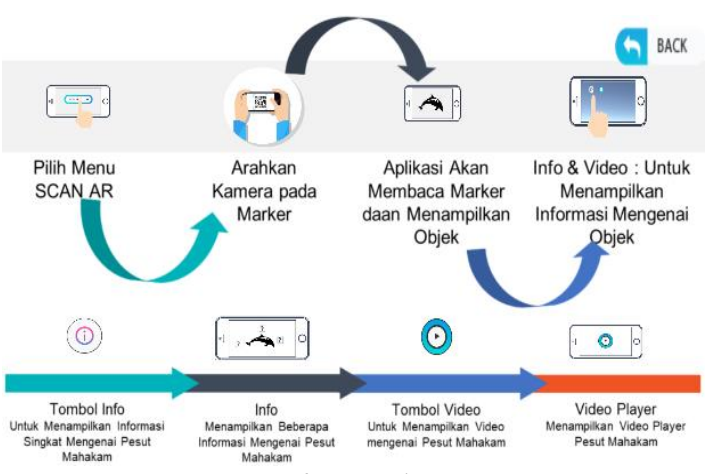

Gambar 3. Interface Halaman Instruction

3) Interface Halaman Marker

Implementasi halaman marker ini yang ditampilkan merupakan gambar marker yang terkait dengan model 3D yang ditampilkan di layar saat pengguna melakukan scan marker. Gambar Marker yang ditampilkan dapat di download. Berikut tampilan Halaman Marker:

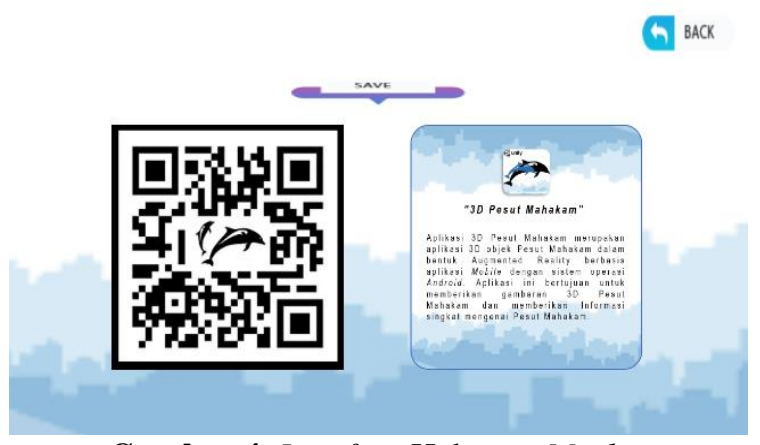

Gambar 4. Interface Halaman Marker

4) Model 3D Pesut Mahakam Pada Scan AR Gambar berikut ini menunjukkan implementasi model 3D pesut Mahakam pada saat marker di scan. Model 3D yang ditampilkan memiliki animasi gerak sederhana pada pesut Mahakam.

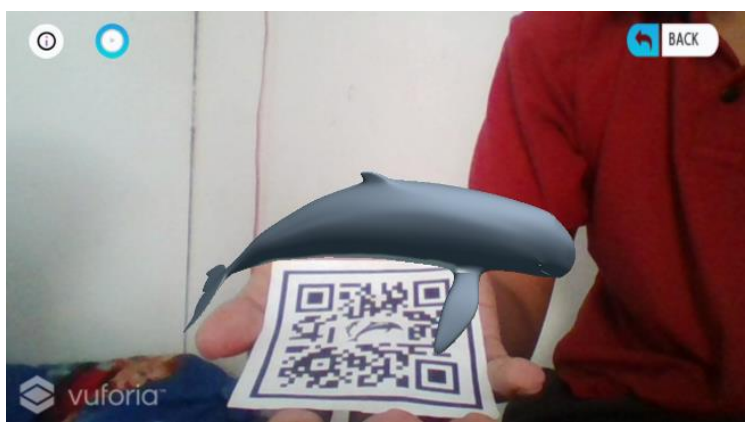

Gambar 5. Model 3D Pesut Mahakam pada halaman Scan AR

5) Info Pada Halaman Scan AR

Halaman Scan $A R$ menampilkan implementasi informasi mengenai pesut Mahakam pada saat tombol info ditekan. Tampilan informasi yang muncul berupa window pada halaman yang dapat di geser untuk menampilkan informasi ciri pesut Mahakam serta bagian-bagian dari tubuh pesut Mahakam. Berikut tampilan informasi mengenai pesut Mahakam:

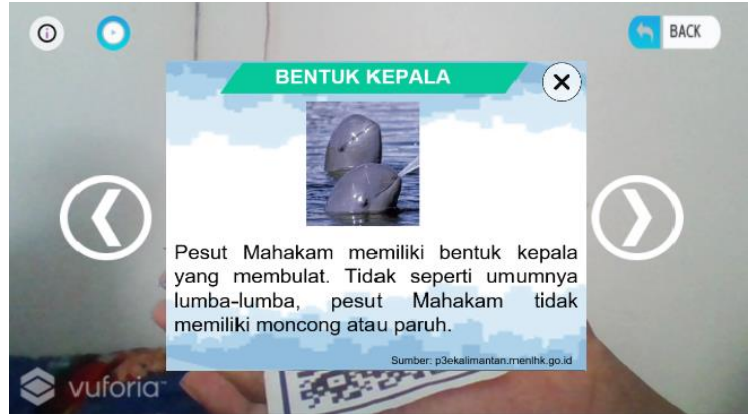

Gambar 6. Informasi Bentuk Kepala pesut Mahakam pada Halaman Scan AR

Gambar 6 menampilkan informasi mengenai bentuk kepala mamalia pesut Mahakam pada saat tombol info ditekan. Informasi yang ditampilkan merupakan penjelasan secara singkat mengenai bentuk kepala pesut Mahakam.

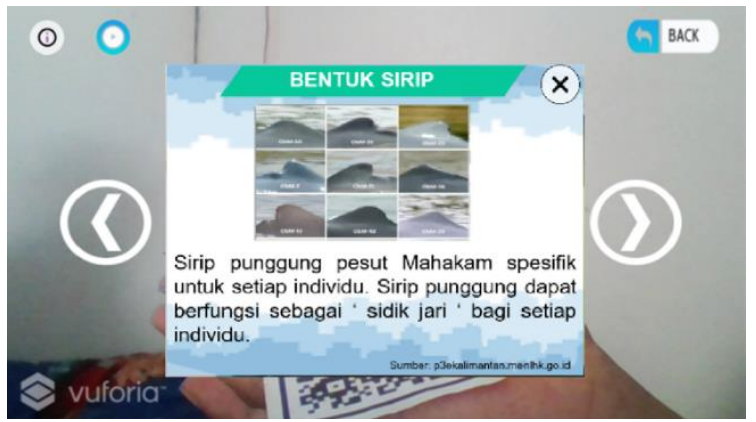

Gambar 7. Informasi Bentuk Sirip pesut Mahakam pada halaman Scan AR

Gambar 7 menampilkan informasi mengenai bentuk sirip punggung mamalia pesut Mahakam dimana bentuk sirip ini menjadi identitas dari setiap individu mamalia pesut Mahakam.

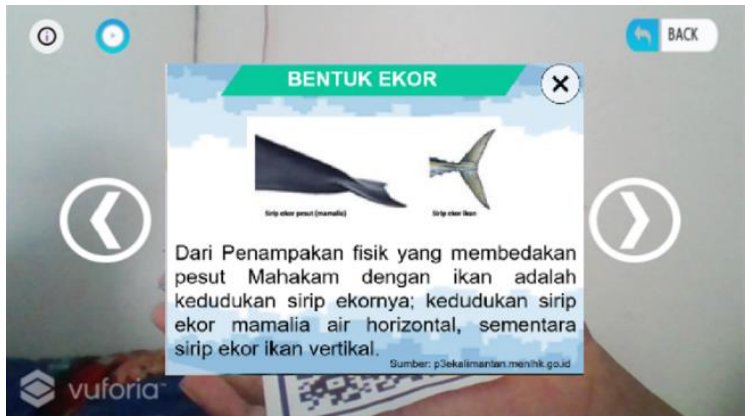

Gambar 8. Informasi Bentuk Ekor pesut Mahakam pada halaman Scan AR

Gambar 8 memberikan informasi mengenai bentuk ekor mamalia pesut Mahakam dimana kedudukan sirip ekor mamalia pesut Mahakam berbeda dengan sirip ekor ikan. Gambar 9 yang memberikan informasi mengenai bentuk badan mamalia pesut Mahakam. 


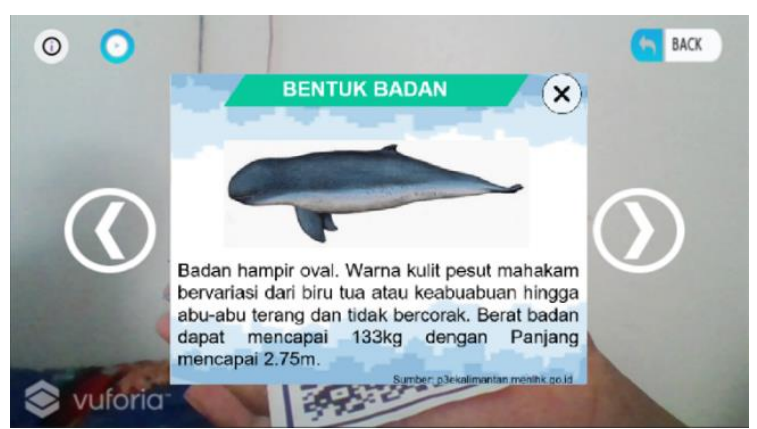

Gambar 9. Informasi Bentuk Badan pesut Mahakam pada halaman Scan AR

6) Info Pada Halaman Scan AR

Saat tombol video ditekan pada halaman Scan AR akan menampilkan implementasi video mengenai pesut Mahakam. Tampilan video yang muncul berupa window pada halaman yang dapat diputar untuk menampilkan video mengenai pesut Mahakam. Berikut tampilan video mengenai pesut Mahakam :

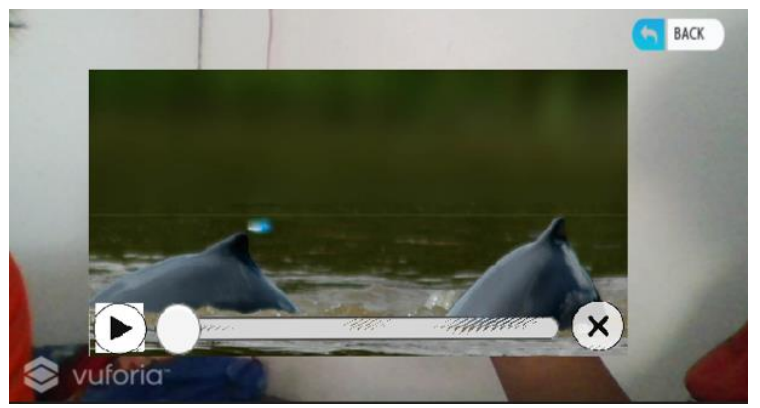

Gambar 10. Video pesut Mahakam pada Halaman Scan $A R$

\section{B. Pengujian Perangkat}

Aplikasi yang berhasil kemudian diuji pada beberapa smartphone untuk melihat apakah aplikasi dapat diinstal dan dioperasikan dengan lancar dan dengan tata letak versi Android dan rasio aspek lapisan tertentu. Tes perangkat dilakukan pada smartphone secara langsung.

Tabel 1. Pengujian Perangkat

\begin{tabular}{|c|c|c|c|c|}
\hline Nama & $\begin{array}{c}\text { Versi } \\
\text { Android }\end{array}$ & $\begin{array}{c}\text { Resolusi } \\
\text { Layar }\end{array}$ & Layout & Status \\
\hline $\begin{array}{c}\text { Galaxy } \\
\text { J7 Prime }\end{array}$ & 9.0 & $\begin{array}{c}1920 \times \\
1080 \\
(16: 9)\end{array}$ & Sesuai & Lancar \\
\hline $\begin{array}{c}\text { Galaxy } \\
\text { J3 Pro }\end{array}$ & 9.0 & $\begin{array}{c}1280 \times 720 \\
(16: 9)\end{array}$ & Sesuai & Lancar \\
\hline $\begin{array}{c}\text { Redmi } \\
\text { Note 5 } \\
\text { Pro }\end{array}$ & 9.0 & $\begin{array}{c}2160 \times \\
1080 \\
(18: 9)\end{array}$ & $\begin{array}{c}\text { Kurang } \\
\text { Sesuai }\end{array}$ & Lancar \\
\hline $\begin{array}{c}\text { Vivo } \\
\text { Y81 }\end{array}$ & 8.1 & $\begin{array}{c}1520 \times 720 \\
(19: 9)\end{array}$ & $\begin{array}{c}\text { Kurang } \\
\text { Sesuai }\end{array}$ & Lancar \\
\hline $\begin{array}{c}\text { Redmi } \\
4 x\end{array}$ & 7.1 & $\begin{array}{c}1280 \times 720 \\
(16: 9)\end{array}$ & Sesuai & Lancar \\
\hline
\end{tabular}

Hasil penelitian menunjukkan bahwa aplikasi Augmented Reality yang dikembangkan pada semua perangkat dapat berjalan dengan lancar pada 5 smartphone versi android yang berbeda dan resolusi layar. Namun untuk kesesuaian layout aplikasi, salah satu perangkat yaitu Vivo Y81 kurang sesuai. Hal ini disebabkan oleh besaran aspek rasio dari perangkat Vivo Y81 adalah 19:9 dimana memang kurang sesuai dalam proses pengembangan aplikasi Augmented Reality ini yang ditunjukkan untuk perangkat dengan aspek rasio 16:9. Ketidaksesuaian layout akan berdampak pada hasil layout front end dari aplikasi yang diuji coba dengan tampilan pada Unity 3D sebelum aplikasi di-build seperti berikut ini:

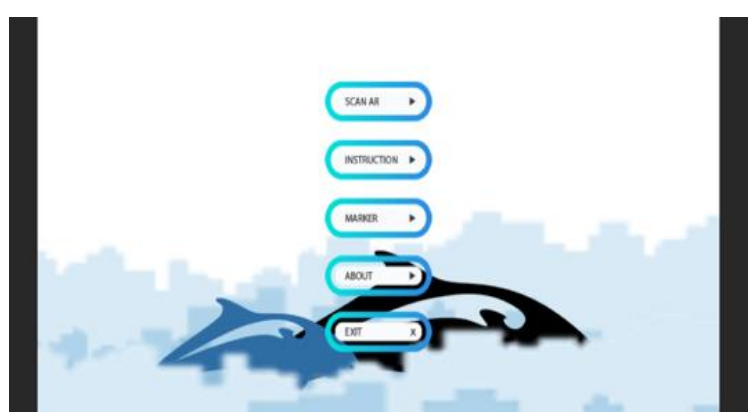

Gambar 11. Ketidaksesuaian Layout Aplikasi

Tampilan halaman instruction pada aplikasi tidak akan terganggu oleh aspek rasio dari perangkat yang digunakan seperti perangkat yang bisa kita lihat pada gambar 12 :

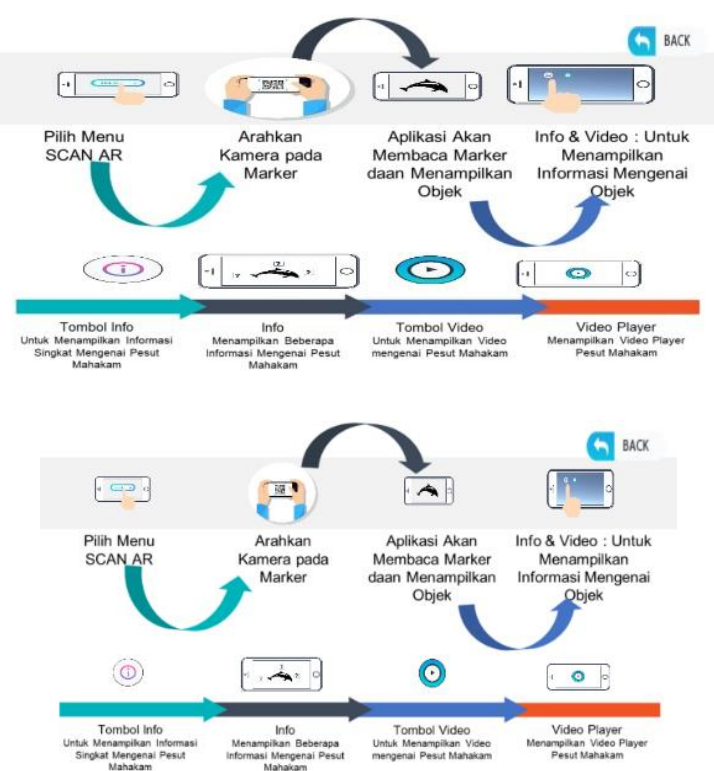

Gambar 12. Aspek Rasio 18:9 (atas) vs Rasio 16:9 (bawah)

Gambar 12 bagian atas diatas merupakan tampilan dari layout pada rasio 18:9 dimana terdapat penyesuaian pada aplikasi dengan tampilan layout yang menyebabkan tampilan sedikit memanjang. Gambar bagian bawah merupakan tampilan dari layout pada rasio 16:9 dimana tampilan pada layout yang sesuai sehingga tampilan terlihat normal. 


\section{Kesimpulan}

Dapat disimpulkan bahwa aplikasi Augmented Reality berdasarkan hasil dan pembahasan yang telah dijelaskan pada bab sebelumnya "3D Pesut Mahakam" berbasis Android telah berhasil dirancang, serta mampu dalam memvisualisasikan objek mamalia pesut Mahakam dan memberikan informasi mengenai pesut Mahakam. Aplikasi "3D Pesut Mahakam", berdasarkan pengujian perangkat, dapat bekerja dengan mudah dengan perangkat Android versi 5.0 hingga Android versi 9.0 dengan rasio 16:9 merupakan perangkat dengan kesesuaian layout terbaik. Berdasarkan hasil evaluasi pada aplikasi Augmented Reality "3D Pesut Mahakam”, Kemudian ada rekomendasi untuk pengembangan aplikasi lebih lanjut bisa di kembangkan tidak hanya Mamalia Pesut Mahakam saja, tetapi hewan lainnya yang juga perlu untuk di lestarikan sehingga cakupan informasinya lebih luas.

\section{Daftar Pustaka}

[1] D. R. Susanto and A. Kiswantoro, "Strategi Pengelolaan Wisata Susur Sungai Mahakam Berbasis Ekowisata di Samarinda," J. Tour. Econ., vol. 3, no. 1, pp. 23-30, 2020.

[2] J. G. Garnada and M. Tohir, "Perancangan Media Kampanye Pelestarian Pesut Mahakam," $e$ Proceeding Art Des., vol. 5, no. 3, pp. 122-127, 2018.

[3] D. Dharmadi, D. I. Hartoto, S. H. Nasution, and D. Oktaviani, "DISTRIBUSI SPASIAL, STATUS PEMANFAATAN, DAN UPAYA KONSERVASI PESUT MAHAKAM (Orcaella brevirostris) DI KALIMANTAN TIMUR," J. Penelit. Perikan. Indones., vol. 15, no. 1, p. 49, 2017, doi: 10.15578/jppi.15.1.2009.49-58.

[4] M. B. Firdaus, E. Budiman, joan angelina Widians, novel maringan Sinaga, S. Fadli, and F. Alameka, "Augmented Reality for Office and Basic Programming Laboratory Peripheral," 2018 2nd East Indones. Conf. Comput. Inf. Technol., vol. 2, no. 2, pp. 41-45, 2018.

[5] M. Br Girsang and R. H, "Desain Permainan 3D Puzzle Dengan Bentuk Hewan Khas Kalimantan," J. Kreat. Desain Prod. Ind. dan Arsit., vol. 9, no. 1, p. 8, 2021, doi: 10.46964/jkdpia.v9i1.148.

[6] K. E. Theodorus, Sukawi, and G. Hardiman, "Pusat Konservasi Pesut Mahakam dengan Pendekatan Arsitektur Ekologis di Kutai Kartanegara, Kalimantan Timur," J. Poster Pirata Syandana, vol. 02, no. 2, p. 15578, 2017, doi: 10.15578/bawal.1.4.2007.127-132.Peraturan.

[7] F. Rahayu, M. Muflihati, S. Anwari, and B. Suriansyah, "PENDUGAAN POPULASI PESUT (Orcaella brevirostris) PADA BULAN FEBRUARI DI RESORT SUNGAI PERLU TAMAN NASIONAL TANJUNG PUTING KALIMANTAN TENGAH," Media Konserv., vol. 25, no. 1, pp. 36-46, 2020, doi:
[8]

10.29244/medkon.25.1.36-46.

D. Oktaviani, S. H. Nasution, and D. Dharmadi, "KEBERADAAN PESUT (Orcaella brevirostris) DI SUNGAI MAHAKAM, KALIMANTAN TIMUR*)," BAWAL Widya Ris. Perikan. Tangkap, vol. 1, no. 4, p. 127, 2017, doi: 10.15578/bawal.1.4.2007.127-132.

[9] M. B. Firdaus, "Pengembangan Alat Ukur Keterbukaan Informasi Publik pada Situs Web Pemerintah Studi Kasus Kabupaten Kutai Kartanegara," J. Ilm. Ilmu Komput., vol. 3, no. 1, pp. 7-13, 2017.

[10] M. B. Firdaus, E. Budiman, Haviluddin, M. Wati, H. J. Setyadi, and H. S. Pakpahan, "An openness of government website content using text analysis method," Int. J. Eng. Adv. Technol., vol. 8, no. 5, pp. 1461-1466, 2019, doi: 10.35940/ijeat.E1214.0585C19.

[11] M. Hasanudin, "Aplikasi E-Commerce Sistem Informasi Penjualan Rolling Door Berbasis Rapid Application Development," Petir, vol. 12, no. 1, 2019, doi: 10.33322/petir.v12i1.368.

[12] H. J. Setyadi, P. P. Widagdo, and T. D. Susanto, "Cognitive age and chronological age of the technostress that effect on satisfaction, performance, and intention of continue the use of information technology in the university," Proceeding - 2017 3rd Int. Conf. Sci. Inf. Technol. Theory Appl. IT Educ. Ind. Soc. Big Data Era, ICSITech 2017, vol. 2018-Janua, pp. 330-335, 2018, doi: 10.1109/ICSITech.2017.8257134.

[13] E. Budiman, M. B. Firdaus, and U. Hairah, "Augmented Reality Peripheral Performance: Light Intensity, Distance, Occlusion and Marker Testing," J. Phys. Conf. Ser., vol. 1898, no. 1, p. 012013, 2021, doi: 10.1088/17426596/1898/1/012013.

[14] J. Prasetiana, "Rancang Bangun Aplikasi Monografi Kecamatan Menggunakan Metode Rapid Application Development (RAD)," vol. 3, no. 3, pp. 41-48, 2019.

[15] A. Tejawati, E. K. Pradana, M. B. Firdaus, F. Suandi, L. Lathifah, and M. K. Anam, "Pengembangan Video Dokumenter 'Wanita Dan Informatika' Di Lingkungan Fkti Universitas Mulawarman," J. Inform. dan Rekayasa Elektron., vol. 2, no. 2, p. 72, 2019, doi: 10.36595/jire.v2i2.121.

[16] I. H. Primananda, N. Santoso, and A. Rachmadi, "Pengembangan Sistem Marketplace Tanah dan Property Berbasis Web dengan Pendekatan Rapid Application Development ( RAD )," Pengemb. Teknol. Inf. dan Ilmu Komput., vol. 4, no. 1, pp. 200-206, 2020, [Online]. Available: http://jptiik.ub.ac.id.

[17] W. Hidayat and N. A. Sudibyo, "Penerapan Multimedia Pembelajaran Interaktif Elektronika dengan Framework RAD (Rapid Application Development) Menggunakan HTML," J. Sains dan Edukasi Sains, vol. 1, no. 2, pp. 17-24, 2018, 
doi: 10.24246/juses.v1i2p17-24.

[18] M. B. Firdaus, J. A. Widians, and R. Rivaldi, "Augmented Reality Marker Based Tracking Kayu Bahan Baku Kerajinan Khas Kalimantan Timur," J. Ilm. Ilmu Komput., vol. 16, no. 1, pp. $1-6,2021$.

[19] A. Fauzi and E. Harli, "Rancang Bangun Sistem Informasi Akademik Smk Negeri 1 Depok Berbasis Android Dengan Pendekatan Rapid Application Development," J. Tek. Inform., vol. 12, no. 2, pp. 129-136, 2019, doi: 10.15408/jti.v12i2.10939.

[20] J. R. Sagala, "Model Rapid Application Development (Rad) Dalam Pengembangan Sistem Informasi Penjadwalan Belajar Mengajar," J. Mantik Penusa, vol. 2, no. 1, pp. 87-90, 2018.

[21] L. Nilawati, "Analisa Model Rapid Application Development Untuk Rancang Bangun Sistem Informasi Penyewaan Apartemen," J. Paradig., vol. XX, no. 2, pp. 33-38, 2018, doi: 10.31294/p.v.

[22] M. B. Firdaus, N. Puspitasari, E. Budiman, J. A. Widians, and N. Bayti, "Analysis of the effect of quality mulawarman university language center websites on user satisfaction using the webqual
4.0 method," Proc. ICAITI 2019 - 2nd Int. Conf. Appl. Inf. Technol. Innov. Explor. Futur. Technol. Appl. Inf. Technol. Innov., pp. 126-132, 2019, doi: 10.1109/ICAITI48442.2019.8982143.

[23] N. Puspitasari, M. B. Firdaus, C. A. Haris, and H. J. Setyadi, "An application of the UTAUT model for analysis of adoption of integrated license service information system," Procedia Comput. Sci., vol. 161, pp. 57-65, 2019, doi: 10.1016/j.procs.2019.11.099.

[24] N. Dengen, H. S. Pakpahan, G. F. Putra, M. B. Firdaus, R. Wardhana, and A. Tejawati, "An Augmented Reality Model Physical Transformation Learning," ICEEIE 2019 - Int. Conf. Electr. Electron. Inf. Eng. Emerg. Innov. Technol. Sustain. Futur., pp. 255-259, 2019, doi: 10.1109/ICEEIE47180.2019.8981444.

[25] A. M. Calle-Bustos, M. C. Juan, F. Abad, and R. Mollá, “An augmented reality app for therapeutic education and suitable for mobile devices with different features," Proc. - IEEE 19th Int. Conf. Adv. Learn. Technol. ICALT 2019, vol. 7, pp. 337339, 2019, doi: 10.1109/ICALT.2019.00106. 